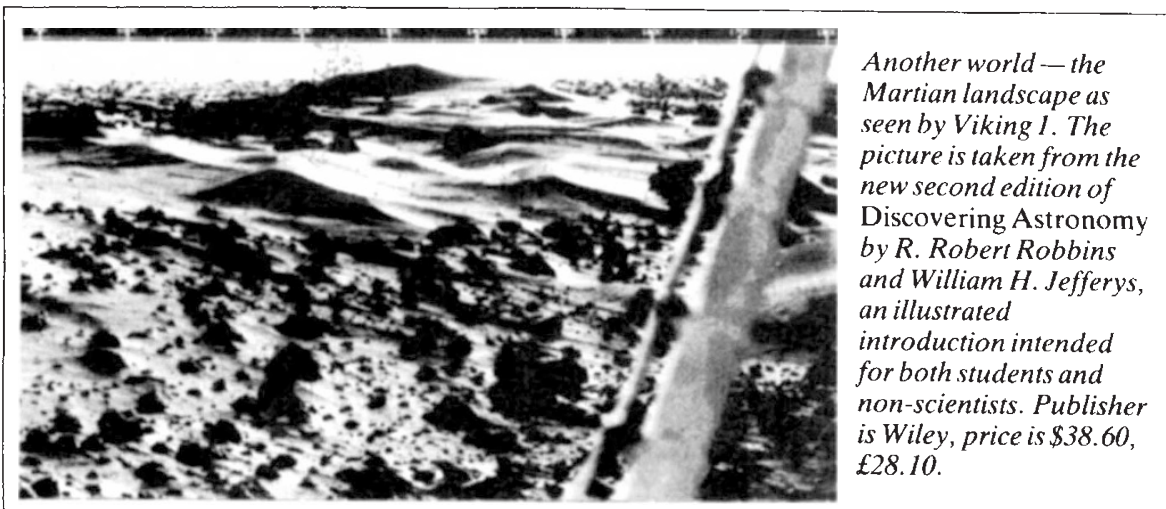

society originated, has continued to meet and flourish up to the present day. For many years it served as an informal link between the leading Fellows.

Throughout the nineteenth century, the amateur members played a leading role both in the society and in astronomical research. Much early astrophysics in Britain was carried out by amateurs, in contrast to today when the expense and complexity of astrophysical equipment demands the involvement of professionals. A hundred years ago, professional astronomers tended to be trained in mathematics and mainly concerned with classical astronomy. The generally nonmathematical nature of early astrophysics appealed to amateur astronomers, and they were responsible for advances in spectroscopy, photography and the development of new types of telescope.

Something else that distinguished the first hundred years of the society's life was the high level of controversy. In 1879, for example Nature commented:

In the interests of British science we have refrained now for some time from referring to the evil days which have fallen upon one of the most reputable of our learned societies.

Surely the Fellows of the Royal Astronomical Society of London are strong enough to remedy such a state of things as this.

Since the editor of Nature was a Fellow of the society, he spoke with inside knowledge. Matters of contention arose throughout the period (1820-1920) covered by the first volume. One of the last actions recorded is the election of the first female Fellows in 1916 after years of sporadic debate.

The second volume covers the period $1920-1980$. It begins with an intriguing episode in the history of British science the inclusion of geophysics in astronomy. In most countries, geophysics was naturally associated with geology. In Britain, the adherence of some of the leading early geophysicists to the RAS, and the lack of interest of the Geological Society (not mentioned in this volume), led to geophysics being organized by the astronomers. That has led to some tension over the years (again somewhat underplayed here), but so have the other specializations that have blossomed within the society. The fact that new activities, such as radioastronomy, have remained within the fold is a tribute to the flexibility of the RAS.

Until well after the Second World War, the running of meetings varied little for decades. The boom in membership during the 1960 s led to a number of changes, but one thing that did not change was the number of amateurs who joined. Their influence, however, was clearly on the decline. The last amateur to be elected president held office 30 years ago. As the introduction to the second volume notes: "by 1980 it had become very rare for someone other than a professional to speak at a meeting, publish a paper or be a member of Council".

Volume 1 of this history first appeared in 1923, three years after the end-date of the history. Volume 2 appeared late last year, seven years after the 1980 end-date, which was itself an extension of the originally intended 1970 deadline. Although it has been revised for publication, some of the material in this volume was therefore written a long time ago. Nevertheless, the two volumes complement each other well, and provide a valuable picture of how a leading British society has developed during its long career.

Jack Meadows, formerly Head of the Department of Astronomy and History of Science at the University of Leicester, is a Professor in the Department of Library and Information Studies, Loughborough University of Technology, Loughborough LE11 $3 T U$, UK.

\section{New journals review}

On 29 September Nature will publish the eighth annual review supplement devoted to science journals. Criteria for inclusion of a journal in the 1988 issue are that:

(i) the first number appeared, or the journal was retitled, between June 1986 and May 1987 (the second cut-off date allows at least three issues of a journal to have been published, the minimum number on which a reasonable judgement can be based);

(ii) it is published at least three times a year; (iii) the main language used is English.

Publishers and learned societies are invited to send four different issues of each suitable periodical, including the first and most recent numbers (if from outside the United Kingdom, by air mail) to: The Review Editor, Nature, 4 Little Essex Strect, London WC2R 3LF, England.

\section{Genetic packages}

\author{
Rodger Staden
}

Sequence Analysis in Molecular Biology: Treasure Trove or Trivial Pursuit? By Gunnar von Heijne. Academic: 1987. Pp.188. \$27.95, $£ 17.50$.

THE methods used to determine DNA sequences are very much faster than the experiments employed to interpret them. Consequently we have to use computers to analyse the sequences and the proteins they encode, and there is a growing number of programs and techniques available for the job. Most users of these programs are not mathematicians or statisticians, but are biologists who are determining a sequence as part of some longer-term scientific project.

The way in which individuals use computing power to analyse their sequences varies enormously. There are still those who are intimidated by computers, while others positively enjoy sitting at a keyboard and trying out all the available forms of analysis. Many people are limited in what they can do, either by being committed to a particular package of programs or simply because they are unaware of other methods that are available.

Publications describing sequenceanalysis software range from the purely mathematical or algorithmic, through more general outlines of what can be done, to thinly disguised advertisements. Von Heijne's book bridges the gaps between these types of publication. It can be read with benefit by all classes of user and also those contemplating entering the field, because it concentrates on conveying the main ideas behind the methods, makes comparisons between them and discusses their reliability.

Most aspects of the subject are covered, ranging from programs to aid laboratory experiments, through DNA-sequence interpretation and prediction of protein secondary structure, to methods of sequence comparison and alignment. The book contains many figures taken from the research literature and is written in a fairly consistently chatty style that makes for easy reading. It is a good introduction, and many readers may subsequently feel more interested in reading the original papers.

The stated take home message is "Don't expect your computer to tell you the truth". I believe that the book will indeed encourage readers to think more clearly about their use of computers for analysing sequences; to ask themselves what questions they really want to answer; and to be more critical of the results they obtain.

Rodger Staden is at the MRC Laboratory of Molecular Biology, Hills Road, Cambridge CB2 $2 Q H, U K$. 